\title{
Marital Status and HIV Prevalence in Nigeria: Implications for Effective Prevention Programmes for Women*
}

\author{
Samson B. Adebayo ${ }^{1,2 \#}$, Richard I. Olukolade ${ }^{3 \#}$, Omokhudu Idogho $^{1}$, Jennifer Anyanti ${ }^{1}$, \\ Augustine Ankomah ${ }^{1,4}$ \\ ${ }^{1}$ The Society for Family Health, Abuja, Nigeria; ${ }^{2}$ National Agency for Food and Drug Administration and Control, Abuja, Nigeria; \\ ${ }^{3}$ Association for Reproductive and Family Health, Abuja, Nigeria; ${ }^{4}$ Department of Population, Family and Reproductive Health, \\ School of Public Health, College of Health Sciences, University of Ghana, Accra, Ghana. \\ Email: " richkolade@yahoo.com
}

Received May 31 ${ }^{\text {st }}$ 2013; revised June 31 ${ }^{\text {st }}$ 2013; accepted July 31 ${ }^{\text {st }}, 2013$

Copyright (C) 2013 Samson B. Adebayo et al. This is an open access article distributed under the Creative Commons Attribution License, which permits unrestricted use, distribution, and reproduction in any medium, provided the original work is properly cited.

\begin{abstract}
Objective: Until recently, HIV prevalence has been based on estimates from antenatal sentinel surveys which have been found to overestimate HIV prevalence among the general population. Multiple studies have shown women to be disproportionately affected by HIV and AIDS epidemic. Design: Data for this study were based on the first Nigerian population household-based HIV biomarker survey of 2007, which used a multi-stage probability sampling technique. Methods: Respondents were selected through probability sampling (male age 15 - 64 years and female 15 - 49 years). This paper, therefore, examined the correlates of marital status and HIV prevalence among women in Nigeria. Results: A descriptive analysis of the data showed that HIV prevalence of women that were formerly married: divorced, separated or widowed were more than double that of those who were currently married/cohabiting with a sexual partner; and more than three times those that were never married. Bivariate and multivariate levels of analysis were explored in this paper. At bivariate level, findings showed a significant difference in HIV prevalence among women according to their marital status $(p<0.0001)$, educational attainment $(p=0.004)$ and geo-political zones $(p=0.003)$. Respondents that were formerly married were 5.6 times as likely to be infected with HIV compared with those who had never married $(\mathrm{OR}=5.6, \mathrm{p}<0.0001)$ while HIV prevalence increased with higher educational attainment. Conclusion: In view of these findings, HIV programmers should design interventions that will improve economic empowerment as well as social security for women that were formerly married. In addition, gender mainstreaming in the ongoing HIV and AIDS preventive efforts should be strengthened and scaled-up.
\end{abstract}

Keywords: Early Marriage; Sexual Initiation; HIV Prevalence; Marital Status; Formerly Married

\section{Introduction}

The Human Immunodeficiency Virus (HIV) and Acquired Immunodeficiency Syndrome (AIDS) have been a major problem in many parts of the world. AIDS was first recognized as a distinct syndrome in 1981 [1]. In Nigeria, about 3.3 million people are infected with HIV with an estimated 220,000 AIDS related deaths [2]. The 2010 National HIV Sero-prevalence sentinel survey conducted among pregnant women attending antenatal clinics in Nigeria put HIV prevalence at $4.1 \%$ [3]. The

\footnotetext{
*Conflict of Interest: The authors have no conflicts of interest to declare.

${ }^{\#}$ Corresponding author.
}

pervading knowledge that women are burden-bearers cannot be said to be untrue, as from the natural and biological point of view, women bear the weight of child birth and the survival of the child greatly depends on the care of the mother. In the same manner, the impact of HIV and AIDS on a global level, but especially in sub Saharan Africa, does not exclude women. This is because HIV is the leading cause of death and disease among women of reproductive age (15 - 49 years) worldwide [4].

Women have constituted approximately half of all adults living with HIV globally and are more likely to become infected than men. It is estimated that for every 
10 men infected, 13 women will be infected. Of the several factors implicated in the unequal prevalence of the disease among women in Africa are economic dependence, feminisation of poverty, unequal distribution of sexual power (sexual violence and coercion), including limited educational opportunities [5]. Sub-Saharan Africa remains the region hardest hit by the HIV epidemic [2]. As is the case in most of sub-Saharan Africa, women greatly surpass men in the number of people living with HIV and AIDS, and in many areas, women double the number of men with the virus [6].

While some long standing socio-cultural practices are reasons for this higher prevalence of HIV among women, other reasons are evolving with changing patterns of behaviour and lifestyle. These reasons include biological and social risk factors [7]. The social factors consist of cultural roles and norms, and harmful traditional practices [8]. Such customs include female genital mutilation, forced marriage, low female child education, and discrimination against the female gender. Protection of girls and women from HIV infection should include protecting them against gender-based violence and promoting economic independence from older men [2]. Social norms that accept extra-marital and pre-marital sexual relationships among men, combined with women's inability to negotiate safe sex practices with their partners make HIV infection a risk even in women who have only had one partner in their entire lives [9]. Men tend to dominate women's sexuality in Africa's dramatic context of poverty [10]. Similarly, in many countries and societies, women and girls are treated as socially inferior [11]. In all these situations, the inability of women to insist on condom use is a "trade off" of their inalienable right for economic advantage.

Biologically, women are two to eight times more likely than men to contract HIV during vaginal intercourse [12] and this may be attributed to difference in anatomical structures of genito-urinary tract which makes females more susceptible to STIs [13]. Since the majority of sexually transmitted infections do not give rise to any symptoms in women, these are less likely to be recognized or treated early enough [9]. During unprotected sex, the virus can also be directly absorbed through the vaginal and cervical mucous membranes. Also, the vaginal lining in women can sometimes tear and possibly allow HIV to enter the body during sex [14].

Marital status is reported to be a factor responsible for the higher HIV prevalence observed among women. Individuals, who are divorced, separated or widowed, tend to have significantly higher HIV prevalence than their counterparts who are single, married, or cohabitating; with divorced or widowed women experiencing especially higher prevalence [8]. For instance, some studies have shown that divorced or separated women in Guinea are more than three times more likely to be infected with HIV than single women, while widowed women are almost seven times more likely to be living with HIV than their counterparts who are single [15]. Meanwhile in Tanzania, studies have shown that more than one in four of widowed women are living with HIV compared with $6 \%$ of those who are married or cohabiting and $2 \%$ of those who have never been married [16].

Furthermore, studies in Uganda showed that the risk of HIV among widowed individuals is almost 5 times higher than that seen in married individuals, while the risk of HIV among separated is twice that of married respondents. This may be because their partners died of AIDS. Most infections are almost three times higher among the divorced and separated than the married [15, 17]. Higher prevalence of HIV in many African countries has been associated with a high rate of marital separation and widowhood [18].

Although a number of HIV and AIDS prevention and intervention efforts are ongoing, and literature on progress made in Nigeria in addressing HIV prevalence is available, yet more needs to be done. In Nigeria, studies are yet to fully examine the relationship between formerly married women within the general population and HIV prevalence especially at national level. This may basically be due to the fact that data to make such inferences are not available until lately.

This paper therefore examines possible correlates of HIV prevalence among women in the general population controlling for their marital status. Findings from this paper will provide HIV programmers and policymakers with the basis for improving and repositioning strategies to combat the disease among women especially in view of higher HIV prevalence among formerly married women compared with their counterparts who were currently in a stable relationship or never married. This paper will also review what target groups would need to be addressed as key populations at risk of HIV.

\section{Data and Methods}

\subsection{Survey Method}

The data used for this study were obtained from the 2007 National HIV \& AIDS and Reproductive Health Survey (NARHS) in Nigeria. The primary objective of the NARHS survey is to provide quantitative data for monitoring current levels of sexual and reproductive health indicators in Nigeria, as well as the impact of reproductive health interventions. The 2007 wave was the third round of the survey in the country with earlier rounds conducted in 2003 and 2005. The 2007 wave was the only one that included a serological component to determine the national HIV prevalence level among the general population. In essence, the 2007 wave was the first 
survey in Nigeria that provided population-based estimates of HIV prevalence in Nigeria. Survey participants were selected across the 36 states and the Federal Capital Territory (FCT) of Nigeria through a multi-stage probability cluster sampling technique at three levels.

Eligible respondents were female aged 15 - 49 years and male aged 15 - 64 years. Selection was based on the sampling frame of enumeration areas which is maintained by the Nigerian National Population Commission (NPC). List of localities was provided by NPC and stratified into major or big towns, medium towns and rural according to the 2006 Population Census. Localities where the surveys were conducted were selected from this list comprising of a mixture of the three main categories with more of rural localities according to the 2006 Nigeria population distribution.

A structured questionnaire which was pre-tested was administered to the respondents. Research personnel were trained with the aim of acquainting them with the survey instruments. Questions were adapted from UNAIDS general population HIV \& AIDS indicator and the Demographic and Health Survey questionnaires. Due to the language complexity in Nigeria (with over 250 languages), questionnaire was designed primarily in English Language. Translations of keywords into local languages were done at a central level training to enhance uniformity and standardisation of questionnaire administration. Enumerators, including HIV \& AIDS counsellors/testers were versed both in English and the local languages of the communities where they worked. For ethical appropriateness, the survey instruments and materials received the approval of the Federal and State Ministries of Health in Nigeria before implementation through the Nigerian Institute of Medical Research. Consent of the respondents was obtained individually and they were adequately informed of the survey objectives upon which an individual has the right to participate or otherwise without any fear of intimidation. A total of 11,822 respondents were selected for the survey but only 11,521 responded to the questionnaire.

An HIV pre-test (to all selected eligible respondents) and post-test (only for those that obliged HIV testing) counselling was offered, while results of the test was provided orally but referrals to facilities for further confirmation and possible placement on treatment for those that were positive. At the end of data collection exercise, the HIV test results were further confirmed on the dried blood samples collected from respondents, in a well-equipped laboratory by an external consultant.

\subsection{Data}

Overall, 5360 women were interviewed in the 2007 NARHS. Of these, only 4195 agreed to be tested after the
HIV pre-test counselling. Therefore, all analyses in this paper were based on the 4195 female respondents that answered the behavioural questionnaire and accepted HIV testing. Marital status was grouped into "Never married, Currently married/cohabiting, and formerly married (i.e. separated, divorced and widowed)". In general, the mean age of the respondents was 27.8 years with a standard deviation (SD) of 9.34. Mean ages according to the marital status are 19.8 years $(\mathrm{SD}=4.90)$ for never married, 30.5 years $(\mathrm{SD}=8.61)$ for currently married/cohabiting, and 35.9 years $(\mathrm{SD}=9.33$ ) for formerly married. Table 1 presents the distribution of the respondents according to marital status and selected characteristics.

\subsubsection{Dependent Variable}

The outcome variable of interest in this study is the result of the HIV test conducted among respondents who were interviewed and volunteered to be tested. For the purpose of this analysis, response indicating positive HIV test was scored " 1 " and " 0 " otherwise.

\subsubsection{Independent Variables}

The key independent variables in this paper are: "marital status", "location of residence", "geo-political zones", "age”, "tribe”, "age at first sex", "experience of sexually transmitted infections (STIs)", "multiple partnering”, "transactional sex i.e. sex in exchange for gifts/favour", religion, "knowledge of HIV prevention", "knowledge of HIV transmission”, and "education”. Marital status with never married as reference category. Place of residence: urban and rural (reference category). Others include educational attainment: Qur'anic/primary, secondary, higher, and no formal education (reference category). Nigeria is divided into six geo-political zones: North West, North East, South West, South East, South South and North Central (the North Central zone was used as the reference). Respondents' age was grouped into four categories; 15 - 19 years, 20 - 24 years, 25 - 34 years, and 35 - 49 years (reference). Tribe was put into: Hausa, Igbo, Yoruba, and others (reference). Religion was classified into three; Christianity, Islam and others (reference).

Background characteristics (demographic variables) and other correlates of HIV prevalence which are important predictors were adjusted for in multiple logistic regression models. These include location, marital status, education, geo-political zones, respondents' age, tribe, religion, knowledge about modes of transmission and prevention of HIV and AIDS, and sexual behavioural indicators such as age at sexual debut, multiple sexual partnering; sex in exchange for gifts, favour or money, and self-report of sexually transmitted infections in the last 12 months. 
Table 1. Descriptive information about the respondents according to demographic characteristics.

\begin{tabular}{|c|c|c|c|c|}
\hline Variables & Never married & Currently married/cohabiting & Formerly married & Total frequency \\
\hline \multicolumn{5}{|l|}{ HIV Status } \\
\hline Positive & 2.9 & 4.0 & 10.6 & 170 \\
\hline Negative & 97.1 & 96.0 & 89.4 & 4025 \\
\hline \multicolumn{5}{|l|}{ Place of residence } \\
\hline Rural & 56.7 & 69.3 & 70.3 & 2761 \\
\hline Urban & 43.3 & 30.7 & 29.7 & 1434 \\
\hline \multicolumn{5}{|l|}{ Educational attainment } \\
\hline None & 5.7 & 36.5 & 42.4 & 1182 \\
\hline Qur’anic & 1.9 & 8.8 & 8.1 & 285 \\
\hline Primary & 10.9 & 24.3 & 28.4 & 870 \\
\hline Secondary & 68.6 & 24.1 & 18.2 & 1524 \\
\hline Higher & 12.9 & 6.3 & 3.0 & 334 \\
\hline \multicolumn{5}{|l|}{ Geo-political zones } \\
\hline North West & 9.5 & 26.1 & 17.4 & 876 \\
\hline North East & 11.1 & 15.9 & 14.0 & 605 \\
\hline North Central & 16.5 & 18.4 & 17.9 & 745 \\
\hline South West & 23.0 & 17.4 & 17.0 & 792 \\
\hline South East & 20.0 & 8.2 & 15.7 & 501 \\
\hline South South & 19.9 & 14.0 & 17.9 & 665 \\
\hline \multicolumn{5}{|l|}{ Ethnicity } \\
\hline Hausa & 16.1 & 37.0 & 21.6 & 1269 \\
\hline Igbo & 23.9 & 10.7 & 17.4 & 621 \\
\hline Yoruba & 22.9 & 17.4 & 19.5 & 799 \\
\hline Others & 37.1 & 34.9 & 41.5 & 1506 \\
\hline \multicolumn{5}{|l|}{ Religion } \\
\hline Islam & 30.4 & 54.5 & 41.1 & 1966 \\
\hline Christian (Catholic and Protestants) & 69.4 & 44.9 & 57.6 & 2201 \\
\hline Traditional/No religion/Others & 0.3 & 0.7 & 1.3 & 24 \\
\hline \multicolumn{5}{|l|}{ Knowledge of mode of HIV transmission } \\
\hline Correct knowledge of all (i.e. all five) & 27.2 & 18.6 & 15.7 & 875 \\
\hline Otherwise & 72.8 & 81.4 & 84.3 & 3320 \\
\hline \multicolumn{5}{|l|}{ Knowledge of mode of prevention } \\
\hline Correct knowledge & 48.2 & 36.4 & 33.1 & 1658 \\
\hline Otherwise & 51.8 & 63.6 & 66.9 & 2537 \\
\hline \multicolumn{5}{|l|}{ Exchange sex for a gift } \\
\hline Yes & 12.7 & 96.5 & 6.0 & 170 \\
\hline No & 87.3 & 3.5 & 94.0 & 3269 \\
\hline \multicolumn{5}{|l|}{ Experienced STI symptoms } \\
\hline Had STI & 12.6 & 89.9 & 90.7 & 452 \\
\hline Did not have STI & 87.4 & 10.1 & 9.3 & 3743 \\
\hline \multicolumn{5}{|l|}{ Age at first sex } \\
\hline First sex below 15 years & 5.1 & 21.0 & 22.0 & 694 \\
\hline 15 years and above & 33.7 & 71.7 & 64.8 & 2543 \\
\hline Never & 59.5 & 0.3 & N/A & 715 \\
\hline Can’t remember & 1.7 & 6.9 & 13.1 & 243 \\
\hline
\end{tabular}

\section{Data Analyses and Results}

\subsection{Descriptive Analysis}

Table 1 presents the descriptive information about the respondents considered in this paper. HIV prevalence was highest among those who were formerly married compared with those currently married/cohabitating, and those who were never married.

Among the formerly married, 6.0\% had exchanged sex for gifts, favour or money, compared with $96.5 \%$ of currently married and $12.7 \%$ of never married who had exchanged sex for gift, favour or money. In general, 90.7\% of those who were formerly married, $89.9 \%$ among currently married/cohabiting respondents, and $12.6 \%$ among never married reported to have experienced STIs.

\subsection{Bivariate Analysis}

Bivariate analyses were performed to establish any significant relationship between HIV status and its correlates i.e. demographic characteristics and other factors that are suspected to be associated with HIV status considered in this paper. In order to assess the degree of association between HIV prevalence (status) and the selected variables, Pearson Chi-square $\left(\mathrm{X}^{2}\right)$ test of association between the dependent and independent variables was used. Results of the bivariate analyses are shown in Table 2. HIV status was found to be significantly associated with marital status. Findings revealed a significant and higher HIV prevalence among women who were formerly married (10.6\%), compared with those currently married (4.0\%) and never married (2.9\%) $(\mathrm{p}<0.0001)$. 
HIV prevalence varies considerably according to educational attainment, geographical regions, age and religion. Respondents with primary education and above are about twice as likely as those with Qur'anic and no formal education to be infected with HIV ( $p=0.004)$. Considering the geo-political zones, HIV prevalence was highest among formerly married women in North Central zone. Results showed that formerly married women in age group 20 - 34 have higher HIV prevalence compared with their counterparts in other age groups $(\mathrm{p}<0.0001)$. HIV prevalence was highest among those practising Christianity (Protestants and Catholics combined) $(\mathrm{p}<$

Table 2. Percentage distributions of the level of HIV prevalence according to selected characteristics. p-values are based on Pearson chi-square $\left(\mathrm{X}^{2}\right)$.

\begin{tabular}{|c|c|c|}
\hline Variables & HIV prevalence & p-value \\
\hline \multicolumn{3}{|l|}{ Place of residence } \\
\hline Rural & 3.7 & \multirow[t]{2}{*}{0.142} \\
\hline Urban & 4.7 & \\
\hline \multicolumn{3}{|l|}{ Marital status } \\
\hline Currently married/cohabiting & 4.0 & \multirow{3}{*}{$<0.0001$} \\
\hline Formerly married & 10.6 & \\
\hline Never married & 2.9 & \\
\hline \multicolumn{3}{|l|}{ Educational attainment } \\
\hline None & 2.6 & \multirow{5}{*}{0.004} \\
\hline Qur'anic & 2.1 & \\
\hline Primary & 5.5 & \\
\hline Secondary & 4.5 & \\
\hline Higher & 5.1 & \\
\hline \multicolumn{3}{|l|}{ Geo-political zones } \\
\hline North West & 2.3 & \multirow{6}{*}{0.003} \\
\hline North East & 4.6 & \\
\hline North Central & 6.3 & \\
\hline South West & 4.0 & \\
\hline South East & 3.8 & \\
\hline South South & 3.5 & \\
\hline \multicolumn{3}{|l|}{ Age categorized } \\
\hline 15 to 19 & 1.4 & \multirow{4}{*}{$<0.0001$} \\
\hline 20 to 24 & 4.4 & \\
\hline 25 to 34 & 6.0 & \\
\hline 35 to 49 & 3.4 & \\
\hline \multicolumn{3}{|l|}{ Tribe } \\
\hline Hausa & 3.4 & \multirow{4}{*}{0.303} \\
\hline Igbo & 4.3 & \\
\hline Yoruba & 3.6 & \\
\hline Others & 4.7 & \\
\hline \multicolumn{3}{|l|}{ Religion } \\
\hline Islam & 2.6 & \multirow{3}{*}{$<0.0001$} \\
\hline Christian (Catholic and Protestants) & 5.3 & \\
\hline Traditional/No religion/Others & 4.2 & \\
\hline \multicolumn{3}{|l|}{ Knowledge of mode of HIV transmission } \\
\hline Correct knowledge & 3.9 & \multirow[t]{2}{*}{0.495} \\
\hline Otherwise & 4.5 & \\
\hline \multicolumn{3}{|l|}{ Knowledge of mode of prevention } \\
\hline Correct knowledge & 3.4 & \multirow[t]{2}{*}{0.011} \\
\hline Otherwise & 5.0 & \\
\hline \multicolumn{3}{|l|}{ Sexual behaviour in the last 12 months } \\
\hline Multiple sexual partners & 13.5 & \multirow[t]{2}{*}{$<0.0001$} \\
\hline Did not & 4.4 & \\
\hline Exchange sex for a gift & & \\
\hline Yes & 5.9 & 0.423 \\
\hline No & 4.6 & \\
\hline Experienced STI symptoms & & \\
\hline Had STI & 6.5 & 0.004 \\
\hline Did not have STI & 3.7 & \\
\hline Age at first sex & & \\
\hline First sex below 15 years & 3.3 & \\
\hline 15 years and above & 5.0 & $<0.0001$ \\
\hline Never & 1.3 & \\
\hline Can’t remember & 4.1 & \\
\hline
\end{tabular}


0.0001) compared with those practising Islam or no religion. Knowledge of modes of prevention and modes of transmission was positively associated with HIV infection. Prevalence was higher among those with incorrect knowledge than those with correct knowledge. This association is only significant for modes of prevention ( $\mathrm{p}=$ 0.011). Respondents that had experienced STIs in the last three months are almost twice as likely to be HIV positive compared with those who have never experienced STIs (6.5 vs. 3.7) $(\mathrm{p}=0.004)$.

Practising multiple sexual partnering showed a significantly positive association with HIV status. Respondents with multiple sexual partners in the last 12 months are over 3 times more likely to be HIV positive compared with those with at most one sexual partner ( $\mathrm{p}<$ 0.0001).

\subsection{Multivariate Analysis}

Multiple logistic regression was used to assess possible association between HIV status and marital status while controlling for other factors. First, a simple logistic regression of the dependence of HIV status on marital status was fitted. This was aimed at investigating the relationship between HIV status and marital status. Hosmer and Lemeshow statistic [19] was used as a test of goodness-of-fit for model checking. While respondents who were currently married or cohabiting with sexual partners were $40 \%(\mathrm{OR}=1.402$, CI: 0.949, 2.073, $\mathrm{p}=0.09$ ) more likely to be HIV infected, those who were formerly married were over three times $(\mathrm{OR}=4.014$, CI: 2.347, 6.867, p < 0.0001) more likely to be HIV infected (results not shown). In addition to marital status; demographic variables were controlled for in a multiple logistic regression model at a further stage. This was aimed at assessing the net-effect of association between HIV status in the presence of demographic variables. Table $\mathbf{3}$ presents findings from the three models reported in this paper. Findings showed significant association with marital status. Respondents who were currently married or cohabiting with sexual partners are $80 \%$ more likely to be HIV infected compared with those never married (OR $=1.80$, C.I.:1.19, 2.88). However, respondents who were formerly married are 5.6 times more likely to be HIV infected (OR = 5.6, CI: 3.09, 10.28).

Education and religion are found to be significantly related to HIV status ( $p<0.05$ ). While respondents with higher education level are 1.4 times more likely to be HIV infected than those with no formal education (OR = 2.4, C.I: $1.21,4.83)$, those with Qur'anic or Primary education are $100 \%$ more likely to be HIV infected than their counterparts with no formal education $(\mathrm{OR}=2.0$, C.I.: 1.25, 3.24). Considerable regional variation exists in HIV prevalence. All regions are less likely to be HIV infected compared with the North Central region.

Model 2 controls for knowledge about modes of prevention and transmissions in addition to the demographic variables controlled for in model 1. The significant association between HIV status and knowledge that was seen in bivariate analysis disappears with the inclusion of other variables. The implication is that, some of the demographic variables can explain this association seen at bivariate level. In model 3 after sexual behaviour indicators were controlled for in addition to Model 2, education was found to be significantly associated with HIV status. Those with Qur'anic or primary education are more than $100 \%$ more likely to be HIV infected than those with no formal education (OR $=2.11$, C.I: 1.29 , 3.431). Those with secondary education are 1.51 times more likely to be HIV infected than those with no formal education (OR = 2.51, C.I: $1.47,4.30)$. Those with higher education are 1.41 times more likely to be HIV positive than respondents without formal education $(\mathrm{OR}=2.41$, C.I.18, 4.91). Also, multiple sexual partnering is significantly related to HIV status. Respondents with multiple sexual partners are 2.87 times more likely to be HIV positive.

\section{Discussions and Conclusions}

This study examines possible determinants of HIV infection among women age 15 - 49 years in Nigeria. Of special interest in this paper is the very high HIV prevalence among formerly married women. At the preliminary analyses, marital status was explored as a proximate correlate of HIV prevalence. To further understand other correlates of HIV infection among this group, attempts were made to control for demographic variables, knowledge and sexual behaviours of the respondents. The aim is to provide more insight into the issue of HIV prevalence among the female group, with a view to providing more information for policy makers and stakeholders interested in the health and quality of life for women in Nigeria and by extension, in the sub Saharan region.

Findings revealed disproportionate HIV prevalence across differential marital levels with formerly married women worst affected. This finding could be attributed to reasons such as lack of economic independence, lack of formal education, low knowledge about HIV transmission and prevention which could result into poor or inability to negotiate safe sex.

In this part of the world, widows are defenceless with no provision for social security on the part of government. On the other hand, the society often stigmatizes divorced women. This double barrelled tragedy has its consequences on women. In addition, in the Nigerian context, and similarly in other part of Africa, women who were once married readily draw the attention of other interested 
Table 3. Estimates of adjusted odds ratios for HIV prevalence from multiple logistic regression.

\begin{tabular}{|c|c|c|c|c|c|c|c|c|c|}
\hline \multirow{3}{*}{ Characteristics } & \multicolumn{3}{|c|}{ Model 1} & \multicolumn{3}{|c|}{ Model 2} & \multicolumn{3}{|c|}{ Model 3} \\
\hline & \multirow{2}{*}{ OR } & \multicolumn{2}{|c|}{ 95\% Conf Int. } & \multirow{2}{*}{ OR } & \multicolumn{2}{|c|}{ 95\% Conf Int. } & \multirow{2}{*}{ OR } & \multicolumn{2}{|c|}{ 95\% Conf Int. } \\
\hline & & Lower & Upper & & Lower & Upper & & Lower & Upper \\
\hline \multicolumn{10}{|l|}{ Marital Status } \\
\hline Never married (ref) & 1.00 & & & 1.00 & & & 1.00 & & \\
\hline Currently married/cohabiting & $1.8^{* *}$ & 1.19 & 2.88 & $1.8^{* *}$ & 1.19 & 2.88 & 1.38 & 0.81 & 2.34 \\
\hline Formerly married & $5.6^{* * * *}$ & 3.09 & 10.28 & $5.60^{* * *}$ & 3.11 & 10.37 & $4.10^{* * *}$ & 2.15 & 8.08 \\
\hline \multicolumn{10}{|l|}{ Locality } \\
\hline Rural (ref) & 1.00 & & & 1.00 & & & & & \\
\hline Urban & 1.24 & 0.87 & 1.77 & 1.23 & 0.87 & 1.76 & 1.21 & 0.84 & 1.76 \\
\hline \multicolumn{10}{|l|}{ Age } \\
\hline 35 to 49 years (ref) & 1.00 & & & 1.00 & & & 1.00 & & \\
\hline 15 to 19 years & 0.53 & 0.18 & 1.51 & 0.54 & 0.19 & 1.56 & 0.51 & 0.67 & 3.95 \\
\hline 20 to 24 years & 1.52 & 0.86 & 2.68 & 1.53 & 0.87 & 2.71 & 1.51 & 0.83 & 2.73 \\
\hline 25 to 34 years & 0.63 & 0.29 & 1.37 & 0.63 & 0.29 & 1.37 & 0.58 & 0.26 & 1.28 \\
\hline \multicolumn{10}{|l|}{ Education } \\
\hline None & 1.00 & & & 1.00 & & & 1.00 & & \\
\hline Qur'anic/Primary & $2.00^{* *}$ & 1.25 & 3.24 & $1.90^{* *}$ & 1.21 & 3.16 & $2.11^{* *}$ & 1.29 & 3.431 \\
\hline Secondary & $2.30^{* *}$ & 1.38 & 3.89 & $2.20^{* *}$ & 1.30 & 3.73 & $2.51^{* *}$ & 1.47 & 4.30 \\
\hline Higher & $2.40^{*}$ & 1.21 & 4.83 & $2.20^{*}$ & 1.10 & 4.54 & $2.41^{*}$ & 1.18 & 4.91 \\
\hline \multicolumn{10}{|l|}{ Religion } \\
\hline Islam \& Others (ref) & 1.00 & & & 1.00 & & & 1.00 & & \\
\hline Christianity & $2.40^{* * * *}$ & 1.59 & 3.85 & $2.40^{* * *}$ & 1.56 & 3.80 & $2.19^{* *}$ & 1.38 & 3.46 \\
\hline \multicolumn{10}{|l|}{ Tribe } \\
\hline Other tribes (ref) & 1.00 & & & 1.00 & & & 1.00 & & \\
\hline Hausa & 1.18 & 0.71 & 1.96 & 1.17 & 0.71 & 1.95 & 1.11 & 0.66 & 1.86 \\
\hline Igbo & 0.89 & 0.40 & 1.99 & 0.89 & 0.40 & 1.99 & 0.97 & 0.43 & 2.21 \\
\hline Yoruba & 0.57 & 0.27 & 1.14 & 0.56 & 0.27 & 1.15 & 0.55 & 0.25 & 1.20 \\
\hline \multicolumn{10}{|l|}{ Geo-political zone } \\
\hline North central (ref) & 1.00 & & & 1.00 & & & 1.00 & & \\
\hline North West & $0.40^{*}$ & 0.23 & 0.83 & $0.40^{*}$ & 0.24 & 0.86 & $0.47^{*}$ & 0.24 & 0.93 \\
\hline North East & 0.90 & 0.52 & 1.52 & 0.89 & 0.52 & 1.53 & 0.96 & 0.55 & 1.69 \\
\hline South East & 0.40 & 0.16 & 0.95 & 0.39 & 0.16 & 0.97 & 0.34 & 0.13 & 0.88 \\
\hline South South & $0.30^{* * *}$ & 0.18 & 0.52 & $0.30^{* * *}$ & 0.18 & 0.52 & $0.29^{* * *}$ & 0.16 & 0.51 \\
\hline South West & 0.70 & 0.35 & 1.42 & 0.69 & 0.34 & 1.40 & 0.67 & 0.31 & 1.42 \\
\hline \multicolumn{10}{|l|}{ Knowledge of modes of HIV prevention } \\
\hline Have no knowledge (ref) & & & & 1.00 & & & 1.00 & & \\
\hline Have knowledge & & & & 1.19 & 0.83 & 1.66 & 1.17 & 0.83 & 1.67 \\
\hline \multicolumn{10}{|l|}{ Knowledge of HIV transmission } \\
\hline Have no knowledge (ref) & & & & 1.00 & & & 1.00 & & \\
\hline Have knowledge & & & & 1.05 & 0.71 & 1.54 & 0.99 & 0.66 & 1.49 \\
\hline \multicolumn{10}{|l|}{ Age at first sex } \\
\hline Never had sex $\&$ below age 15 (ref) & & & & & & & 1.00 & & \\
\hline Above 15 years & & & & & & & 1.15 & 0.70 & 1.89 \\
\hline
\end{tabular}




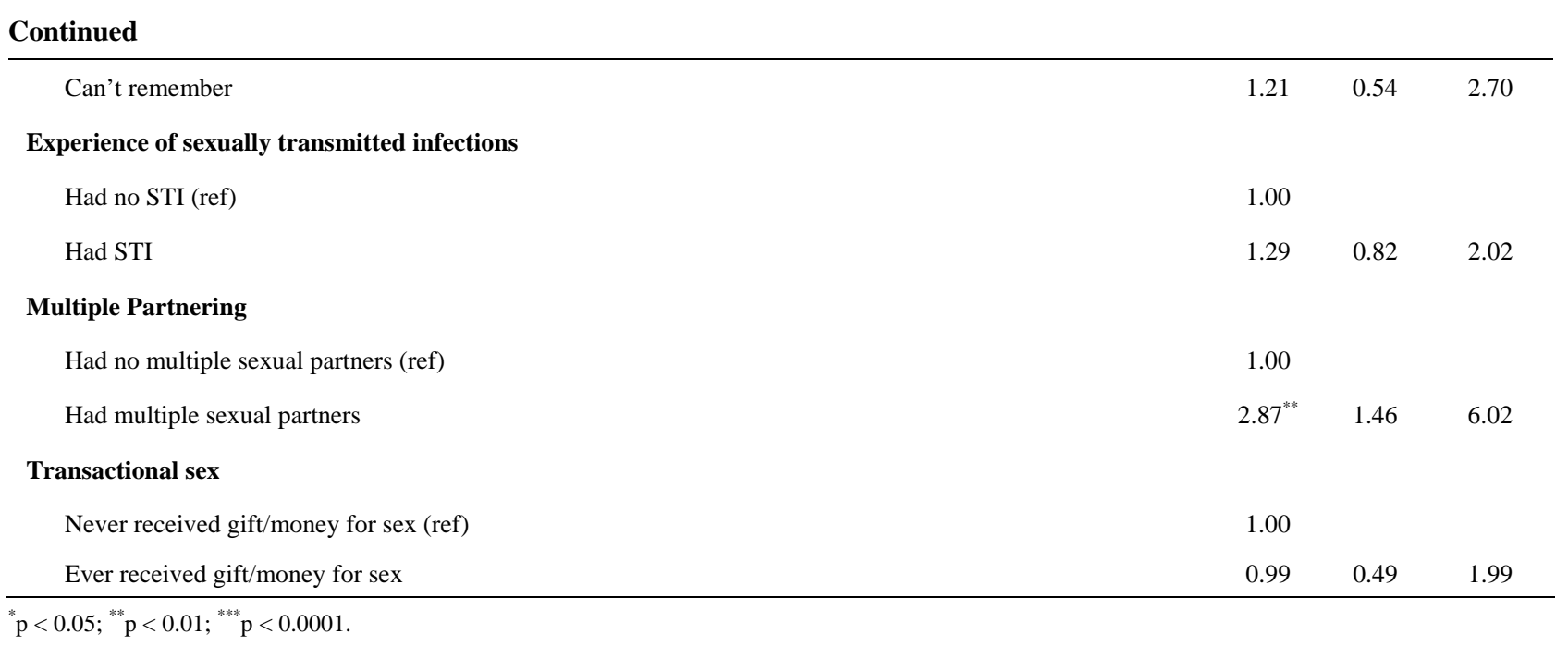

male partners who may promise to relieve their economic burden, but in disguise, only want to establish a sexual relationship. The low ability of a large proportion of $\mathrm{Ni}-$ gerian women to negotiate safer sex and offer an alternative safe method, such as use of the female condom, are likely to have also contributed to the heightened probable causes of the findings of this study.

The harsh economic condition that culminated into high rate of unemployment irrespective of the educational status, and high cost of living, may also likely be responsible for this problem. The erosion of moral values in the society cannot be undermined. The high tendency of linking people who were formerly married with behaviour that is considered improper and immoral may have also prevent many women in this category from seeking HIV Counselling and Testing (HCT). In this paper, most independent variables considered were significantly associated with HIV prevalence at bivariate level. These relationships were further established at the multivariate level. This provided evidence that special intervention strategies are necessary to stem this tide. Findings revealed geographical variations in HIV prevalence across geo-political zones. Highest prevalence was observed in the North Central. To gain better insight into the geographical variations of HIV prevalence, an analysis at a highly disaggregated level of states will be useful for policy formulation. This is consequent on the fact that information may be masked at the geopolitical level since each geo-political zone comprises of six to seven states. This will provide policy makers with adequate tools for enhancing effective HIV \& AIDS preventive interventions. From the fitted logistic models, it became apparent that multiple sexual partnering was a key determinant of HIV infection among women with a higher proportion of formerly married females engaged in multiple sexual partnering.

A key insightful finding from this study suggests that gender mainstreaming in the on-going preventive efforts should be strengthened and scaled-up, to particularly target formerly married women. Findings further reinforce the need for economic empowerment, social security and welfare relief packages for women in this category. HIV programming and policies that focuses on formerly married women will continue to reduce the incidence and prevalence of HIV and AIDS amongst this group and at large, among women in general.

\section{Limitations of the Study}

The data used for this paper were obtained from a single round of a national survey. This means that trend cannot yet be ascertained. In order to further assess the vulnerability of formerly married women to contracting HIV and AIDS, data at more time points will be desirable. As in any cross-sectional study, causal relationships cannot be established. Therefore, one cannot be certain whether some of the factors precede or post-date HIV infection, given the asymptomatic nature of HIV. Furthermore, information on sexual behaviour was based on self-reported responses by the respondents.

\section{Acknowledgements}

The authors would like to thank the Federal Ministry of Health of Nigeria for granting us the permission to use the 2007 NARHS data sets. The grants from DFID and USAID to implement this survey are gratefully acknowledged. Appreciation goes to colleagues at the Research and Evaluation Division of the Society for Family Health Nigeria for reading the first draft of this paper. Their comments have led to substantial improvement of this manuscript.

The work was carried out in a collaborative effort. AA, JA, and SBA designed the survey, wrote the survey protocol and supervised data collection. SBA and RIO 
carried out the data analyses. All authors read and approved the final manuscriptt.

\section{Conflicts of Interest and Sources of Funding}

None of the authors declared any conflict of interest. The 2007 National HIV \& AIDS and Reproductive Health Survey Plus from where data for this paper was generated, was funded by the United States Agency for International Development (USAID) and the British Department for International Development with the support of the Federal Government of Nigeria.

\section{REFERENCES}

[1] J. Mann, “AIDS,” World Health Forum, Vol. 8, 1997, pp. 361-370.

[2] UNAIDS, “Report on the Global AIDS Epidemic,” 2010. http://www.unaids.org/globalreport/documents/20101123 _GlobalReport_full_en.pdf

[3] Federal Ministry of Health, “Technical Report of National HIV Sero-Prevalence Sentinel Survey among Pregnant Women Attending Antenatal Clinics in Nigeria," Department of Public Health, National AIDS/STI Control Programme, 2011.

[4] UNAIDS Fact Sheet, "Women, Girls, and HIV Overview,” 2010. http://www.unaids.org

[5] B. E. Wodi, "Gender Issues in HIV/AIDS Epidemiology in Sub-Saharan Africa," 2005. http://appweb.cortland.edu/ojs/index.php/Wagagu/article/ viewArticle/245/ 454.

[6] World Health Organization, "AIDS Epidemic Update: Special Report on HIV/AIDS,” 2006.

http://www.who.int/hiv/mediacentre/2006_EpiUpdate_en. pdf

[7] S. Maman, J. Campbell, M. D. Sweat and A. C. Gleen, "The Intersections of HIV and Violence: Directions for Future Research and Interventions," Social Science and Medicine, Vol. 50, No. 4, 2000, pp. 459-478. doi:10.1016/S0277-9536(99)00270-1

[8] UNAIDS and WHO, "AIDS Epidemic Update 2009," 2009. http://data.unaids.org/pub/Report/2009/jc1700_epi_updat e_2009_en.pdf
[9] World Health Organization, "Gender and HIV/AIDS," 2003. http://www.who.org

[10] L. Finley, “The AIDS Pandemic,” (2006). Retrieved from: http://the-aids-pandemic.blogspot.com/2006/11/women-a nd-hivaids-in-africa.html

[11] World Health Organization, "Women and Health: Today's Evidence, Tomorrow's Agenda,” World Health Organization, Geneva, 2009.

[12] UNAIDS and WHO, “AIDS Epidemic Update 2007,” 2007.

http://data.unaids.org/pub/epislides/2007/2007_epiupdate _en.pdf

[13] A. Abdulazeez, E. Alo and R. Naphthali, "Concurrent Infection of HIV-1 and HIV-2 Serotypes in Adamawa State Nigeria,” World Journal of Medical Sciences, Vol. 3, No. 1, 2008, pp. 15-18.

[14] Center for Disease Control and Prevention, "HIV Transmission,” 2010.

http://www.cdc.gov/hiv/resources/qa/transmission.htm

[15] H. Neondo, "HIV Falling but High among Divorced, Widowed,” Africa Science News Service, 2009. http://africasciencenews.org/asns/index2.php?option=com _content\&do_pdf=1\&id=1811

[16] National Bureau of Statistics [Tanzania] and ORC Macro, “Tanzania Demographic Health and Survey 2004-2005," 2005.

http://www.measuredhs.com/pubs/pdf/FR173/FR173-TZ 04-05.pdf

[17] I. Kasamba, D. Maher, S. Biraro, H. Grosskurth and J. Todd, "How HIV Prevalence, Number of Sexual Partners and Marital Status Are Related in Rural Uganda," XXVI IUSSP International Population Conference, Marrakech, 2009.

http://iussp2009.princeton.edu/download.aspx?submissio nId $=92459$

[18] J. T. Boerma, M. Urassa, S. Nnko, J. Ng’weshemi, R. Isingo, B. Zaba and G. Mwaluko, "Sociodemographic Context of the AIDS Epidemic in a Rural Area of Tanzania with a Focus on People's Mobility and Marriage," Sexually Transmitted Infections, Vol. 78, No. S1, 2002, pp. S97-S105. doi:10.1136/sti.78.suppl 1.i97

[19] D. W. Hosmer and S. Lemeshow, “Applied Logistic Regression,” John Wiley, New York, 1989. 